\title{
A large sedimentary basin in the Terra Sirenum region of the southern highlands of Mars
}

\author{
Alfonso F. Davila ${ }^{\mathrm{a}, \mathrm{b}, *}$, Christoph Gross ${ }^{\mathrm{c}}$, Giuseppe A. Marzo ${ }^{\mathrm{b}, \mathrm{d}, 1}$, Alberto G. Fairén ${ }^{\mathrm{a}, \mathrm{b}}$, Thomas Kneissl ${ }^{\mathrm{c}}$, \\ Christopher P. McKay ${ }^{\mathrm{b}}$, James M. Dohm ${ }^{\mathrm{e}}$ \\ a SETI Institute, Carl Sagan Center for the Study of Life in the Universe, 515 N. Whisman Road, Mountain View, CA 94043, USA \\ ${ }^{\mathrm{b}}$ Space Sciences and Astrobiology Division, NASA Ames Research Center, Moffett Field, CA, USA \\ ${ }^{\mathrm{c}}$ Freie Universitaet Berlin, Institute of Geological Sciences, Planetary Sciences and Remote Sensing, D-12249 Berlin, Germany \\ ${ }^{\mathrm{d}}$ Bay Area Environmental Research Institute, 560 Third St. West, Sonoma, CA 95476, USA \\ e University of Arizona, Department of Hydrology and Water Resources, 1133 East James E. Rogers Way, Tucson, AZ 85719, USA
}

\section{A R T I C L E I N F O}

\section{Article history:}

Received 17 June 2010

Revised 23 November 2010

Accepted 22 December 2010

Available online 28 December 2010

\section{Keywords:}

Evaporites

Basin

Highlands

Noachian

Water

\begin{abstract}
A B S T R A C T
Different lines of evidence point to hydrological cycling in the martian past. The extent, duration, and magnitude of this cycling remains unclear, as well as the magnitude of aqueous processes on the surface. Here, we provide geomorphic and mineralogic evidence of a large inter-crater sedimentary basin located in the Terra Sirenum region, which was once covered by a body of liquid water with an areal extent of at least $30,000 \mathrm{~km}^{2}$ and a depth of approximately $200 \mathrm{~m}$. The topographic basin, which is modified by a number of large impact craters, is partly controlled by ancient impact and tectonic structures. As a result of evaporation of the large body of water, salt flats formed in the lowest topographic reaches of the basin. Hydrated phyllosilicates occur in close proximity to the salt flats and in the ejecta and rim materials of small impact craters with stratigraphic relations that suggest that they underlie the evaporite deposits. Crater statistics place the maximum age of aqueous activity during the Late Noachian epoch. The relatively pristine mineral deposits in the basin have a high potential to yield information of the geochemistry and water activity during the ancient Noachian Period when conditions were seemingly more conducive to life.
\end{abstract}

(c) 2010 Elsevier Inc. All rights reserved.

\section{Introduction}

There is ample evidence of water flowing and ponding on the surface of Mars in the past, including widespread phyllosilicates (e.g., Poulet et al., 2005; Bibring et al., 2006; Mustard et al., 2008), salt deposits including sulfates and chlorides (Squyres et al., 2004; Gendrin et al., 2005; Osterloo et al., 2008, 2010), elevated elemental concentrations (Dohm et al., 2009), and geomorphic features such as valley networks, fluvial channels, layered sedimentary deposits, paleolakes, and deltas (e.g., Masursky et al., 1977; Carr and Clow, 1981; Scott et al., 1995; Carr, 1996; Cabrol and Grin, 1999; Malin and Edgett, 2001; Fairén et al., 2003; Di Achille and Hynek, 2010). Such lithologies, elemental concentrations, and geomorphic features point to hydrological cycling in the past. However, the extent, duration, and magnitude of this cycling remains unconstrained.

\footnotetext{
* Corresponding author at: Space Sciences and Astrobiology Division, NASA Ames Research Center, Moffett Field, CA, USA.

E-mail address: adavila@seti.org (A.F. Davila).

1 Present address: NEA, C.R. Casaccia, UTFISST-RADSITO, via Anguillarese 301, 00123 S. Maria di Galeria, Roma, Italy.
}

Recent studies have reported the presence of diverse hydrated minerals over large parts of the ancient cratered southern highlands (Mustard et al., 2008; Grant et al., 2008; Murchie et al., 2009; Wray et al., 2009). Many of these minerals occur in rock outcrops, which are associated with impact craters. Secondary minerals in impact craters on Mars can have three possible origins: impact excavation of buried deposits (e.g., Ehlmann et al., 2009; Fairén et al., 2010), local post-impact water activity, consistent with ancient crater lakes (e.g., Cabrol et al., 2001; Orofino et al., 2009; Marzo et al., 2010), or impact-induced hydrothermal activity (Marzo et al., 2010; Fairén et al., 2010). In the first case, information about the origin and formational conditions of the deposits is largely altered (if not destroyed) due to the impact and associated exhumation processes. Excavated aqueous deposits are not necessarily representative of aqueous processes on the surface, since the minerals could have formed below the surface with subsequent exposure through impact cratering. Rather, post-impact crater deposits are more indicative of water activity at the surface, though they may only relate to the local (intra-crater) environment in which they formed (Marzo et al., 2010; Fairén et al., 2010). In both cases, it is difficult to infer the duration and extent of the aqueous processes involved in the formation of the deposits. 
Extensive inter-crater sedimentary basins in ancient terrains, on the other hand, are windows into the ancient aqueous processes that took place on the surface of Mars. Sediments within these ancient basins contain information of the geochemistry of early martian waters and the environmental conditions at the time of formation, provided that these deposits have not been significantly altered by subsequent geologic processes. Irwin et al. (2002) described a $1,000,000 \mathrm{~km}^{2}$ Noachian lake in the ancient cratered southern highlands, which drained northward, sculpting one of the larger martian valleys, Ma'adim Vallis. However, no mineralogic evidence was presented of aqueous deposits inside the basin (Irwin et al., 2002). Wray et al. (2009) recently identified Fe/Mgphyllosilicates in the inter-crater plains on Sirenum and Noachis Terrae, associated with putative-chloride-bearing deposits. Both studies hint at the existence of large bodies of liquid water on the surface of the highlands in the past.

Based on geomorphic and mineralogic evidence, we describe a large inter-crater sedimentary basin in the Terra Sirenum region, which contains aqueous deposits including evaporites and phyllosilicates that formed early in the history of the planet. These sedimentary deposits could contain information of the geochemistry and aqueous activity from a period when conditions were seemingly more conducive to life. Though geologic processes such as impact cratering events, volcanism, erosion, and deposition have modified the basin, geomorphic and mineralogic features are still observable, pointing to a pervasive ancient aqueous martian environment.

\section{Physiographic and geologic setting}

The inter-crater basin is located approximately $300-400 \mathrm{~km}$ northeast of Newton impact crater in the Terra Sirenum region (Fig. 1). The basin occurs in an ancient geologic province marked by distinct magnetic signatures (Connerney et al., 1999; Acuña et al., 1999, 2001), relatively high density of large degraded impact craters, and faults and ridges (Scott and Tanaka, 1986; Zuber, 2001). The basin floor is characterized by mostly dark-albedo surfaces through daytime THEMIS images, and which are the center of this investigation. The basin contains previously reported chloride-bearing deposits, likely formed in an evaporitic environment within the ancient geologic province of Terra Sirenum (Osterloo et al., 2008, 2010). Similar chloride-bearing deposits appear to be common in the southern highlands between $25^{\circ}$ and $40^{\circ}$ of latitude (Osterloo et al., 2008, 2010; Murchie et al., 2009; Wray et al., 2009).

\section{Methods}

\subsection{Satellite images and spectral data}

Diverse orbiting spacecraft information was used in this study to investigate the area of interest in the Terra Sirenum region. The information included: (1) images from the High Resolution Imaging Science Experiment (HiRISE) (up to $25 \mathrm{~cm} /$ pixel; McEwen et al., 2007) and Context (CTX; $6 \mathrm{~m} /$ pixel; Malin et al., 2007) cameras on the Mars Reconnaissance Orbiter (MRO); (2) topographic data from the Mars Global Surveyor (MGS) Mars Orbiter Laser Altimeter (MOLA) (altitude resolution of $13 \mathrm{~m}$, Zuber et al., 1992); (3) multi-band images through the Mars Odyssey (ODY) Thermal Emission Imaging System (THEMIS) (100 m/pixel nearinfrared (IR) day and nighttime images and $18 \mathrm{~m} /$ pixel visible multi-band images; Christensen et al., 2003); and (4) the Compact Reconnaissance Imaging Spectrometer for Mars (CRISM) (hyperspectral observations with a spatial resolution approximating $\sim 18 \mathrm{~m}$ /pixel; Murchie et al., 2007). CRISM, in particular, measures reflected radiation in the visible and near infrared (VNIR) from the surface of Mars, providing the ability to recognize both primary (e.g., pyroxenes) and secondary minerals (e.g., clays). CRISM spectral data was converted to apparent $I / F$ (the ratio of reflected to incident sunlight), then divided by the cosine of the incidence angle to correct for the illumination geometry (Murchie et al., 2007, 2009); the atmospheric contribution was removed using a volcano-scan correction (McGuire et al., 2009).

THEMIS IR data was used to identify chloride-bearing deposits within the basin, previously reported by Osterloo et al. (2008, 2010). The chloride-bearing deposits appear blue in THEMIS IR decorrelation stretched images using bands 8, 7, and 5 (Osterloo et al., 2008) (Fig. 2). Context (CTX) and high-resolution (HiRISE) images were used to map and characterize evaporites (morphology, size, surface texture, patterned ground, etc.), as well as other

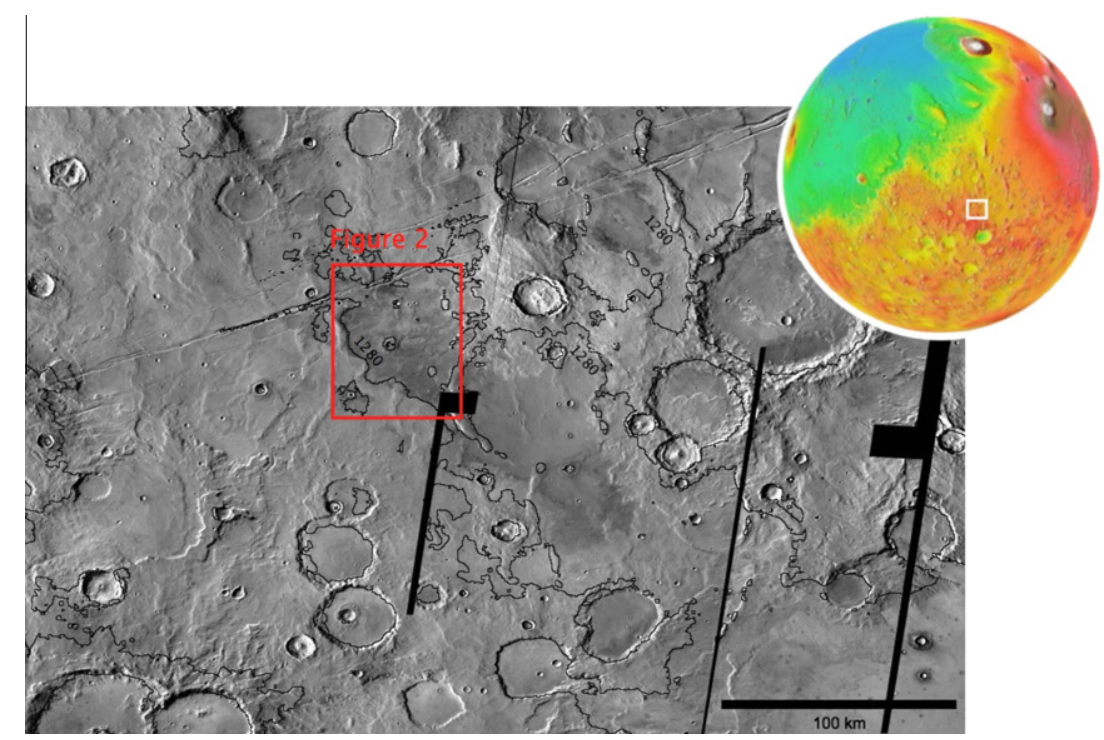

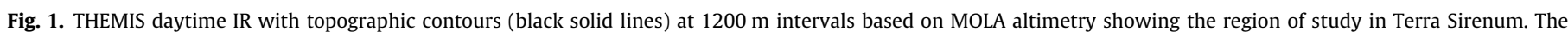

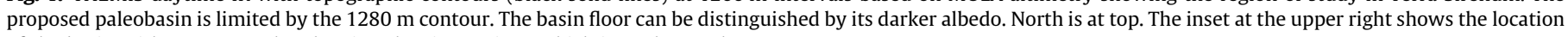
of the basin with respect to the Tharsis volcanic province which is to the northeast. 

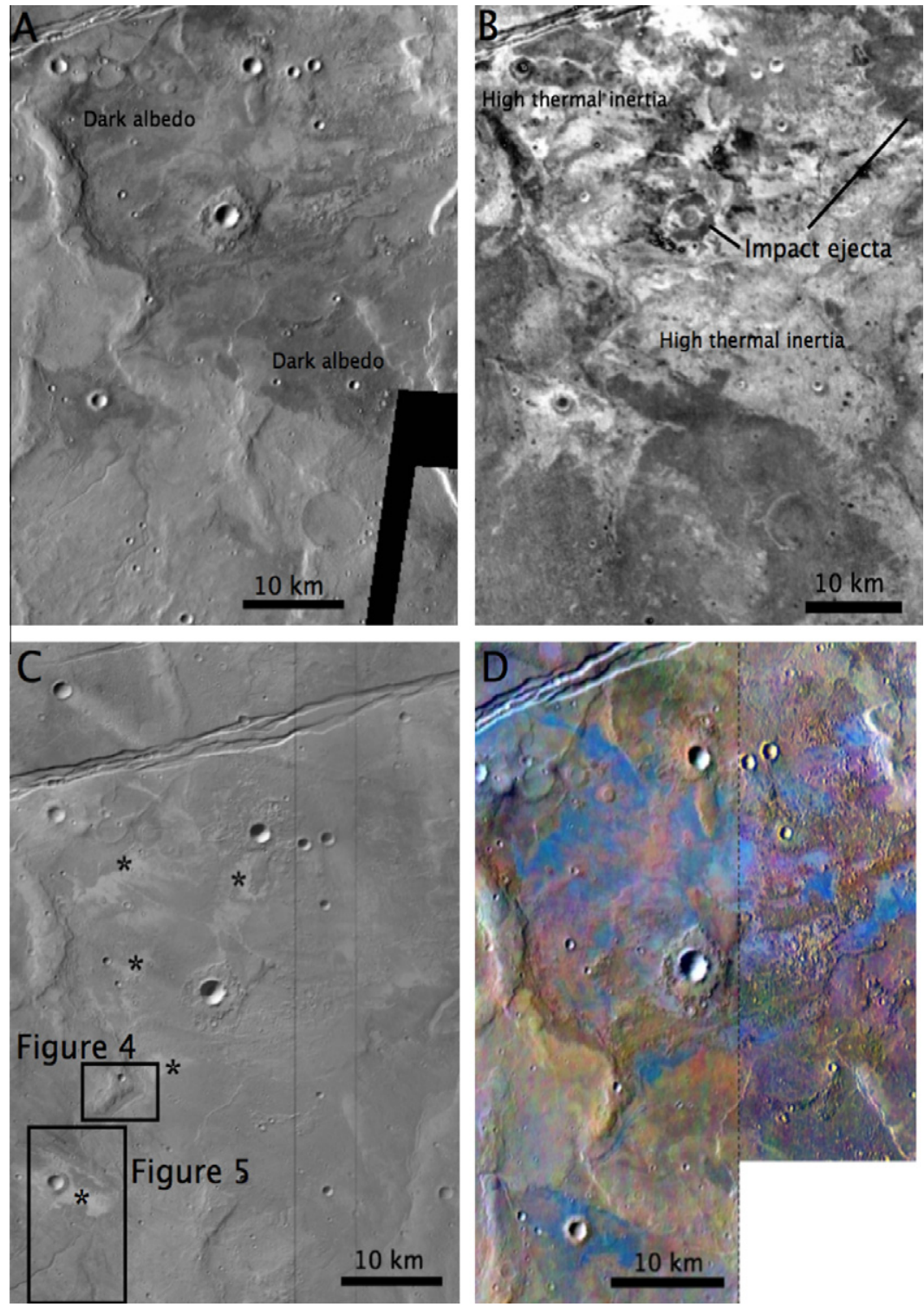

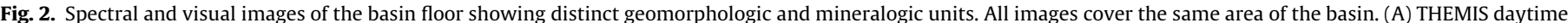

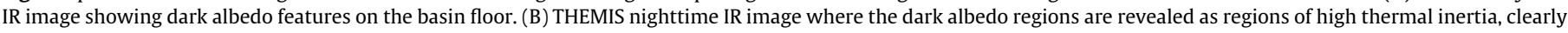

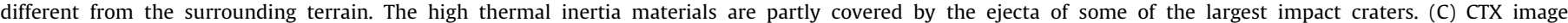

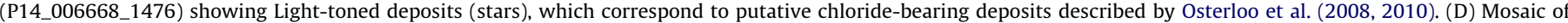

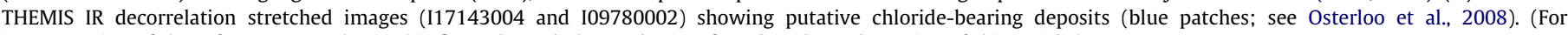
interpretation of the references to color in this figure legend, the reader is referred to the web version of this article.)

geomorphological features inside and around the basin, including faults, impact craters, and channels and other fluvial landforms. Phyllosilicate-bearing deposits were mapped based on the presence of the $2.3 \mu \mathrm{m}$ spectral absorption feature using the D2300 parameter index defined by Pelkey et al. (2007). Average spectra of areas with high values $(>0.01)$ of the D2300 were extracted from the CRISM observations. These average spectra were then ratioed to a featureless spectrum to enhance the unique spectral features and minimize remaining calibration and atmospheric artifacts.

\subsection{Crater counts}

Statistical analysis of crater size-frequency distributions (CSFD) of impact craters on planetary surfaces is an established method to derive relative formation ages on the basis of remote sensing image data (e.g., Oepik, 1960; Shoemaker et al., 1962; Baldwin, 1964;
Hartmann, 1965). We used a CTX image mosaic comprised of the images P14_006668_1476_XI_32S154W, P18_008171_1473_XN_ 32S154W, and P21_009318_1463_XI_33S154W ( 5.61 m/pixel) (same as Fig. 3) to determine the cratering model age of the basin materials, which included some of the phyllosilicate- and saltbearing deposits. The target area was divided into several parts based on morphology and texture. We used the software "CraterTools" for map-projection-independent crater size-frequency determinations for the area of interest described by Kneissl et al. (2010). Output of this tool comprises correct impact-crater diameters and area sizes and can be used for relative-age determinations. The statistical analysis of determined CSFDs has been done using the program "Craterstats" described by Michael and Neukum (2010). Impact-crater diameters were segmented into bins of increasing crater diameter and plotted into cumulative, crater size-frequency distribution diagrams with corresponding 


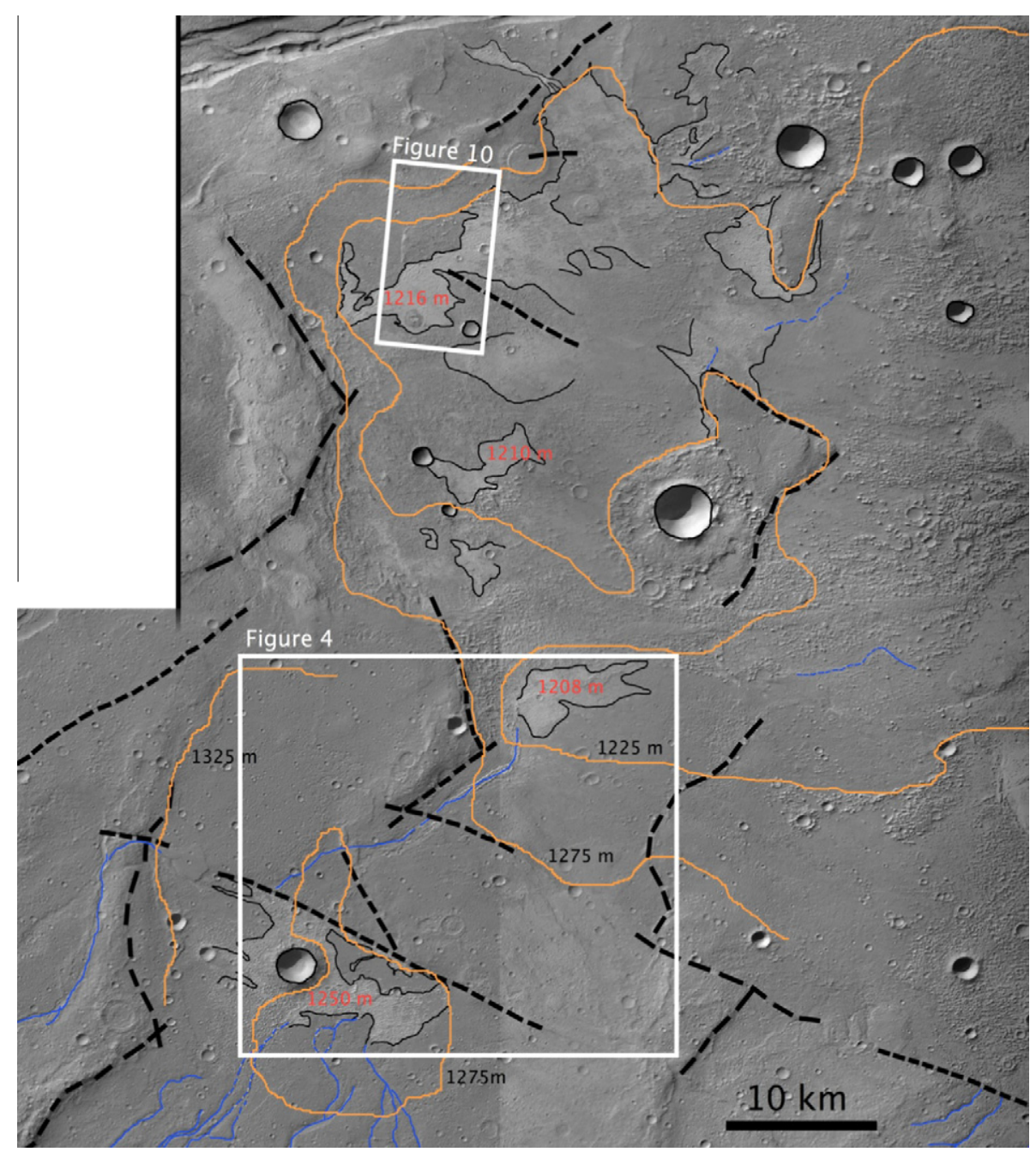

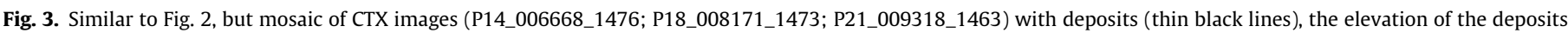

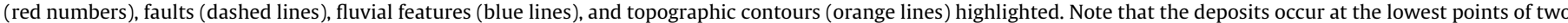

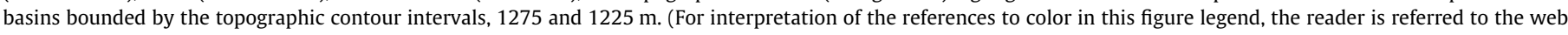
version of this article.)

statistical errors. The established martian impact crater production function (Ivanov, 2001) was statistically fitted to the observed crater size-frequency distribution. The derived $N(1)$ value was then used to obtain cratering model ages from the martian chronology function derived by Hartmann and Neukum (2001).

\section{Results}

\subsection{Basin geomorphology and mineralogy}

The sedimentary basin extends mostly to the south of the Sirenum Fossae fault system. THEMIS daytime IR images of the basin revealed patches of dark albedo deposits with a relatively smooth surface, which appear to be partly influenced by topography (Fig. 2a). The same patches are revealed as high thermal inertia materials using nighttime THEMIS images (Fig. 2b). High thermal inertia can be due to exposed bedrock, rockier or more indurated terrain, or coarser particle sizes on the surface (Putzig et al., 2005). While these patches appear to be partly covered by the ejecta of well-preserved impact craters, such as a relatively large impact to the east (approximately $20 \mathrm{~km}$ diameter), in turn, they also appear to blanket older structures and materials such as from ancient, highly eroded impact structures. At higher resolution, this high thermal inertia surface coincides with putative chloride-bearing deposits (Osterloo et al., 2008), which appear as light-toned outcrops in HiRISE and CTX images (Fig. 2c), and as blue deposits in THEMIS IR decorrelation stretched images (Fig. 2d) (Osterloo et al., 2008). We have identified up to 6 isolated deposits in this area, which are interpreted here as salt flats based on both the morphological and mineralogic evidences presented below. We thus refer to these as salt flats throughout the remainder of the text.

All the salt flats have the same appearance and texture, including irregular edges that resemble shorelines and fractured surfaces with polygons. The spatial distribution of the salt flats appears to be controlled by the local topography, and all of them can be placed inside a basin defined by the $1280 \mathrm{~m}$ contour, which also coincides with a break in slope. Smooth and ridged plains are located below the $1280 \mathrm{~m}$ contour, whereas higher-standing terrain is generally steeper and dissected. All the salt flats appear at the lowest points of the basin, between $1208 \mathrm{~m}$ and $1250 \mathrm{~m}$. The primary basin appears to be structurally controlled as it is elongated to the northwest with faults forming parts of its margin (Fig. 3). Although the salt flats cover a relatively large area, they appear to share a common origin. For example the two southernmost salt 
flats, which occur at different topographic levels (almost an elevation difference of $50 \mathrm{~m}$ ) are connected by a channel that is partially filled with materials similar in texture, albedo, and morphology to those that form the salt flats. The complex interplay among the channel and its drainage and the ridges and faults is observed in cases where the channel is structurally controlled while in other cases the channel transects topography such as a ridge that occurs between the salt flats shown in Fig. 4 .

The southernmost salt flat is also associated with a system of fluvial channels (Fig. 5), which debouch directly into a local basin from the south-southwest to form the evaporite deposits. Some of the channels are inverted at their lower parts, near their juncture with the salt flat. The inverted channels appear to be comprised of the same evaporite deposits, forming fan structures at their termini. The channels originate between 10 and $20 \mathrm{~km}$ to the south from seemingly discrete points at higher topographic levels with respect to the salt flat. Ejecta deposits of a 2-km-diameter impact carter partly cover the salt flat at the its central part, and thus the salt flat must have formed prior to the impact event. There is a relatively large number of smaller impact craters on and around the salt flat. A channel transects a ridge along a fault to the southwest of the salt flat, and debouches into the basin to form a delta-like landform (see Fig. 5).

In addition to the salt flats that indicate the flow, ponding, and evaporation of water, a series of outcrops of hydrated minerals have been identified using CRISM data. All the spectra present similar features throughout the region. The average spectrum from CRISM observation HRL0000860C, which is located in the northwestern edge of the basin (see Fig. 3), is reported in Fig. 6. The CRISM spectra has a prominent band at $1.92 \mu \mathrm{m}$, which indicates hydration typically due to the presence of bound $\mathrm{H}_{2} \mathrm{O}$ (Bishop et al., 1994). An absorption feature near $1.42 \mu \mathrm{m}$ is also present, indicative of hydroxylated minerals (Clark et al., 1990). Based on the shape and position of the broad band centered at $2.31 \mu \mathrm{m}$, the spectrum is suggestive of $\mathrm{Fe} / \mathrm{Mg}$-phyllosilicates. The distribution of phyllosilicate-bearing deposits in this area is shown in Fig. 7b.

Phyllosilicate-bearing deposits in this area are closely related to the salt flats, and appear in the ejecta and rims of craters that impacted the evaporitic deposits (Fig. 8), suggesting that phyllosilicates could be more abundant beneath the evaporitic deposits, a sequence consistent with terrestrial cycles of siliciclastic deposition followed by evaporation. Hydrated minerals were also identified in a small area north of the Sirenum Fossae (Fig. 7c); the absorption feature near $1.42 \mu \mathrm{m}$ and the shape and position of the broad band centered at $2.31 \mu \mathrm{m}$ are linked to $\mathrm{Fe} / \mathrm{Mg}$ phyllosilicates. The hydrated deposits coincide with an area of irregular terrain with knobs and large boulders that appear to derive from the degradation of the surrounding plains. The phyllosilicate signature is closely linked to the knobs and boulders, suggesting that the hydrated deposits are mantled by nonhydrated materials, and are only exposed following the break up of the terrain and/or deflation of the non-hydrated surface cover through wind-related processes.

We found a third region with hydrated minerals in the northwestern part of the basin (Fig. 7d), which are also interpreted to be Fe/Mg-phyllosilicates based on their spectral features. The total extent of hydrated minerals at this site cannot be determined due to the limited CRISM coverage. This region is defined by semi-circular ridges, which are interpreted to be the rim materials of a heavily eroded crater, approximately $45 \mathrm{~km}$ in diameter. The crater is barely distinguishable as there are other degraded impact crater rims and possibly wrinkle ridges superimposed on it, and it has been partly infilled with sediments. Topographically, this part of the basin is the lowest, with a minimum depth of $1085 \mathrm{~m}$ at its center. The materials that partly infill the highly degraded basin are cut by faults of the Sirenum Fossae to the North. This region is separated from the other sites with hydrated minerals by a relatively large, fresh-looking impact crater whose ejecta partly blankets the deposits of both areas. The basin infill deposits likely

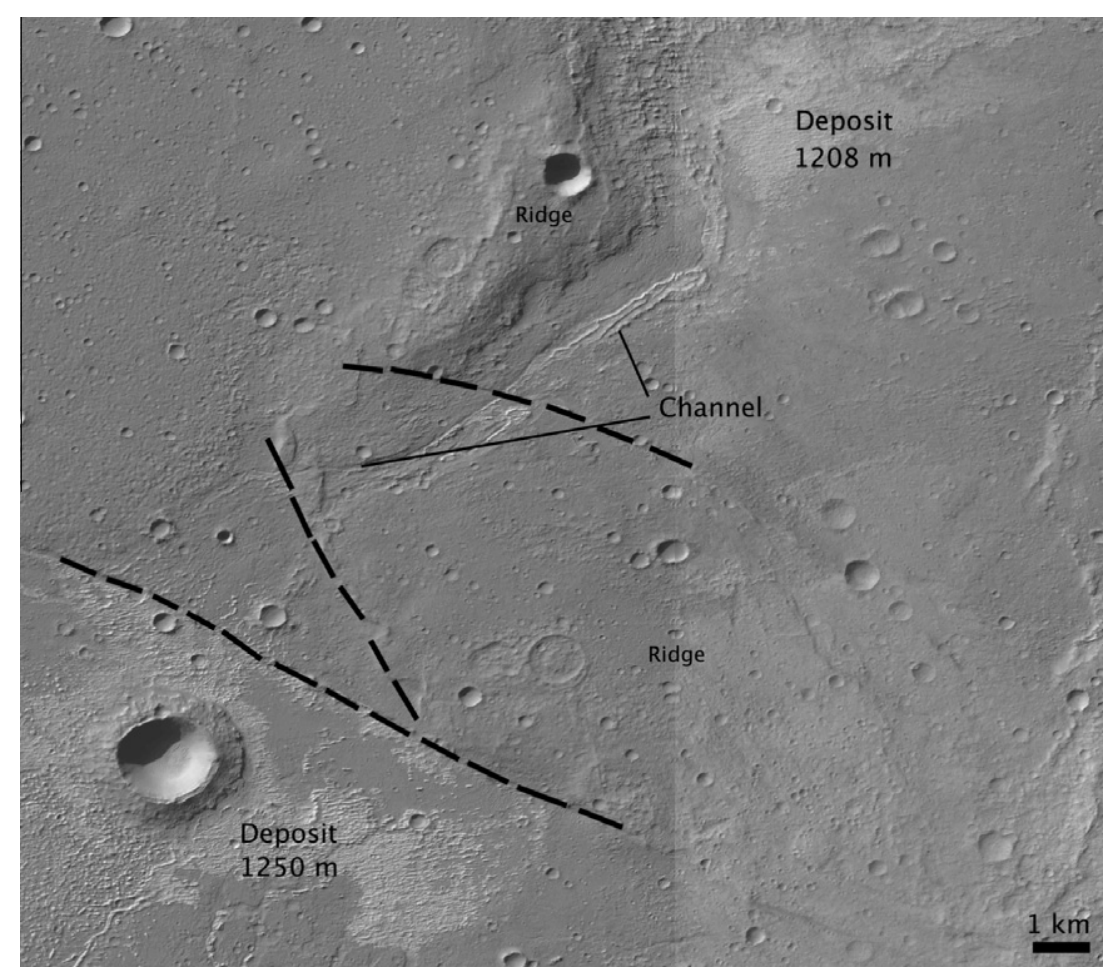

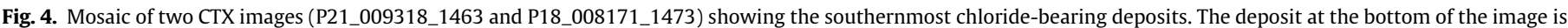

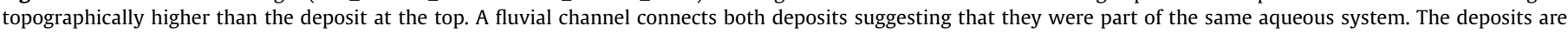
separated by ridges, likely formed as a result of tectonic activity, as evidenced by the presence of faults (dashed lines). 

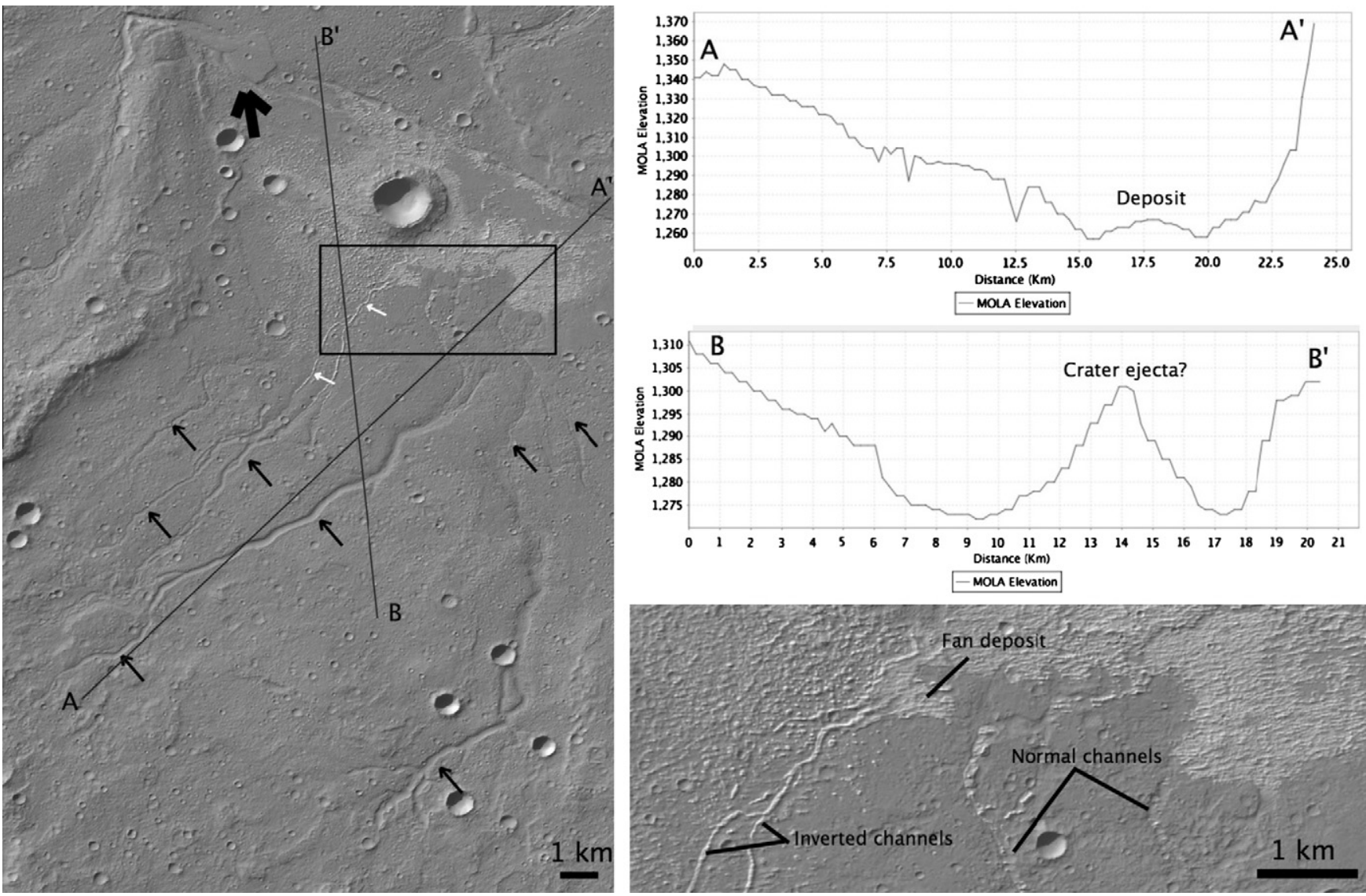

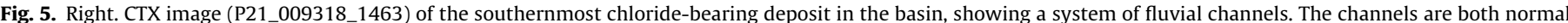

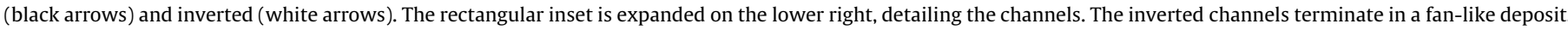

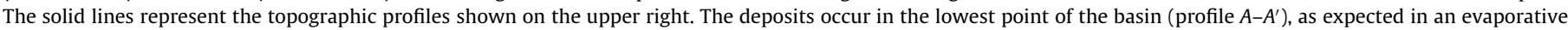

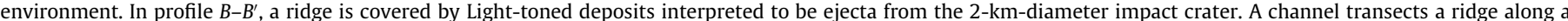

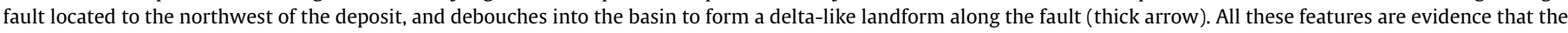
deposit formed in the presence of water.

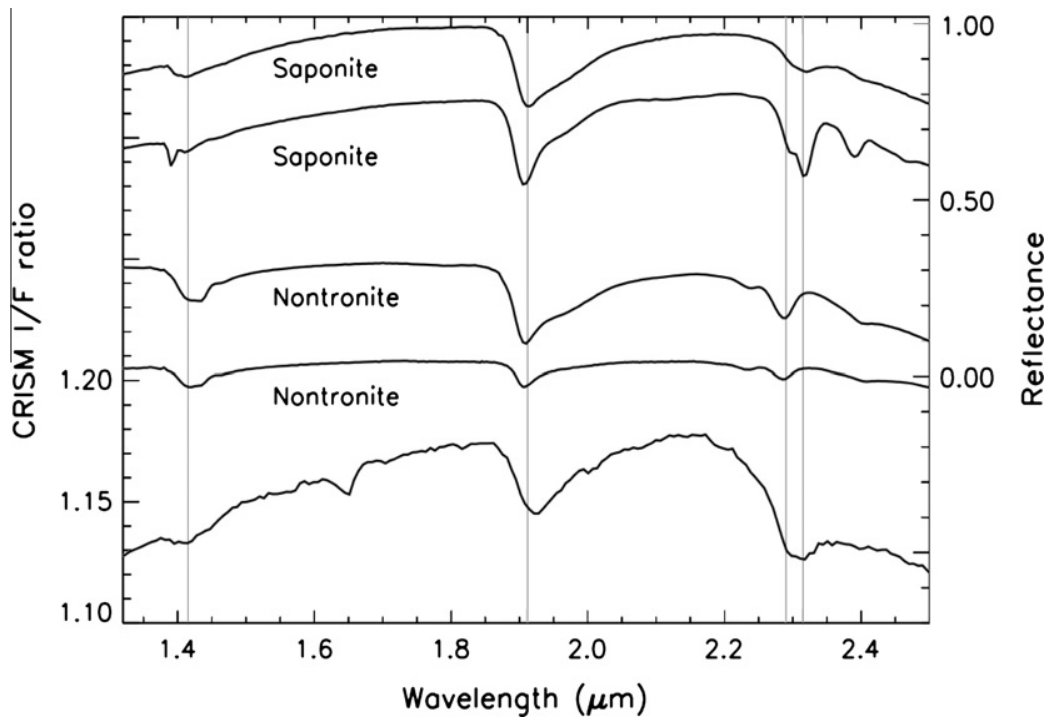

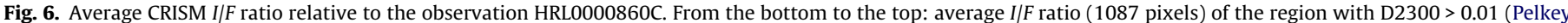

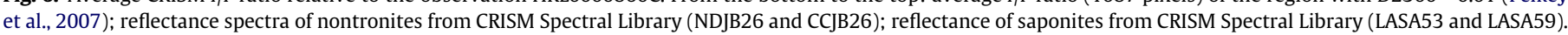

predate both the formation of the Terra Fossae faults (at least locally) and the fresh-looking impact crater.

Though there is no CRISM coverage to the south of the basin, we have identified a system of fluvial channels using CTX images, which could be associated with the same aqueous processes that resulted in the formation of the hydrated minerals and evaporite deposits. The fluvial channels terminate at the $1280 \mathrm{~m}$ topographic contour, supporting the hypothesis that this 

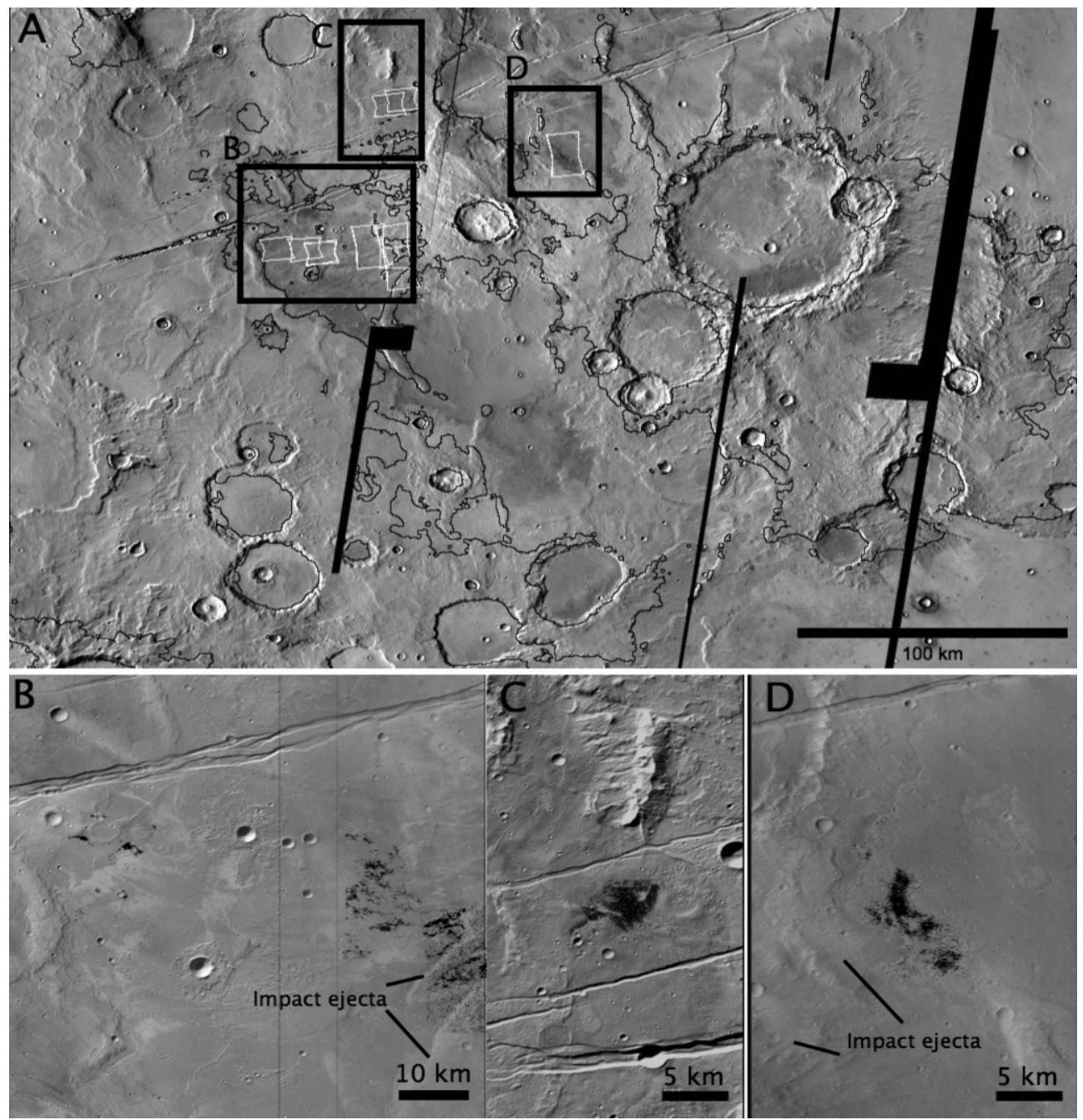

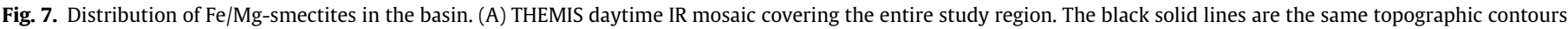

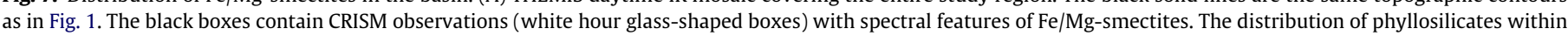

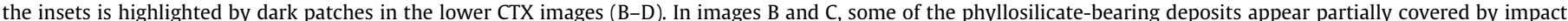

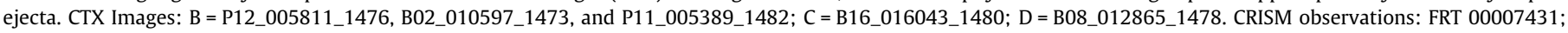
FRT 0000A102; FRT 0000A941; FRT 0000AB81; FRT 00011D8A; FRT 00012E44; HRL000123D7; HRL00006823; HRL00007C95; HRL0000D002.

contour might define the water level of a paleosedimentary basin (Fig. 9).

Fig. 10 places all the geomorphologic and mineralogic information presented above into the regional context of the basin. Evaporites and phyllosilicates occur on the basin floor below the $1280 \mathrm{~m}$ topographic contour, which we interpret as a paleoshoreline of the basin. Fluvial features terminate at this contour. Large impact craters modified the basin, and therefore it is difficult to establish its total aerial extent. Spectrally distinct areas identified using THEMIS IR and CRISM data all occur within the proposed basin.

\subsection{Crater statistics}

A base age for the entire basin was determined using impact craters with sizes $>400 \mathrm{~m}$, showing an absolute model age of $3.95+0.06 /-0.11 \mathrm{Ga}$. A modeled resurfacing age can be detected at $3.6+0.06 /-0.11 \mathrm{Ga}$ (Fig. 11), indicating a second episode of surface modification. We also determined the ages of the light-toned deposits. Here, we used crater sizes $>20 \mathrm{~m}$. The light-toned materials show a patchwork-like distribution within the area. Furthermore, the deposits show moderate differences in albedo presumably resulting from different degrees of alteration and erosion. The brightest and therefore probably the best preserved deposit shows an age of 3.6 + 0.11/-1.0 Ga which is in good agreement with the result of the resurfacing age determination of the overall basin. The resurfacing age of this light-toned deposit indicates an age of $313 \pm 100 \mathrm{Ma}$. Taken into account that the basin materials show a highly altered and eroded surface, the resulting resurfacing age derived from the counting of small crater sizes should only be used with caution and considered as an indicator of major resurfacing events. This age could be regarded as the final major stage of surface modification of the light-toned deposits likely due to wind erosion.

\section{Discussion and summary}

Osterloo et al. $(2008,2010)$ reported extensive deposits in the cratered highlands with a spectral signature that could not be matched with other hydrated phases observed on Mars, interpreting these deposits as chloride-bearing materials. Some of these deposits appear within the newly identified paleolake basin of the Terra Sirenum region described here. Geomorphologic evidence indicating an evaporative origin for these deposits includes 


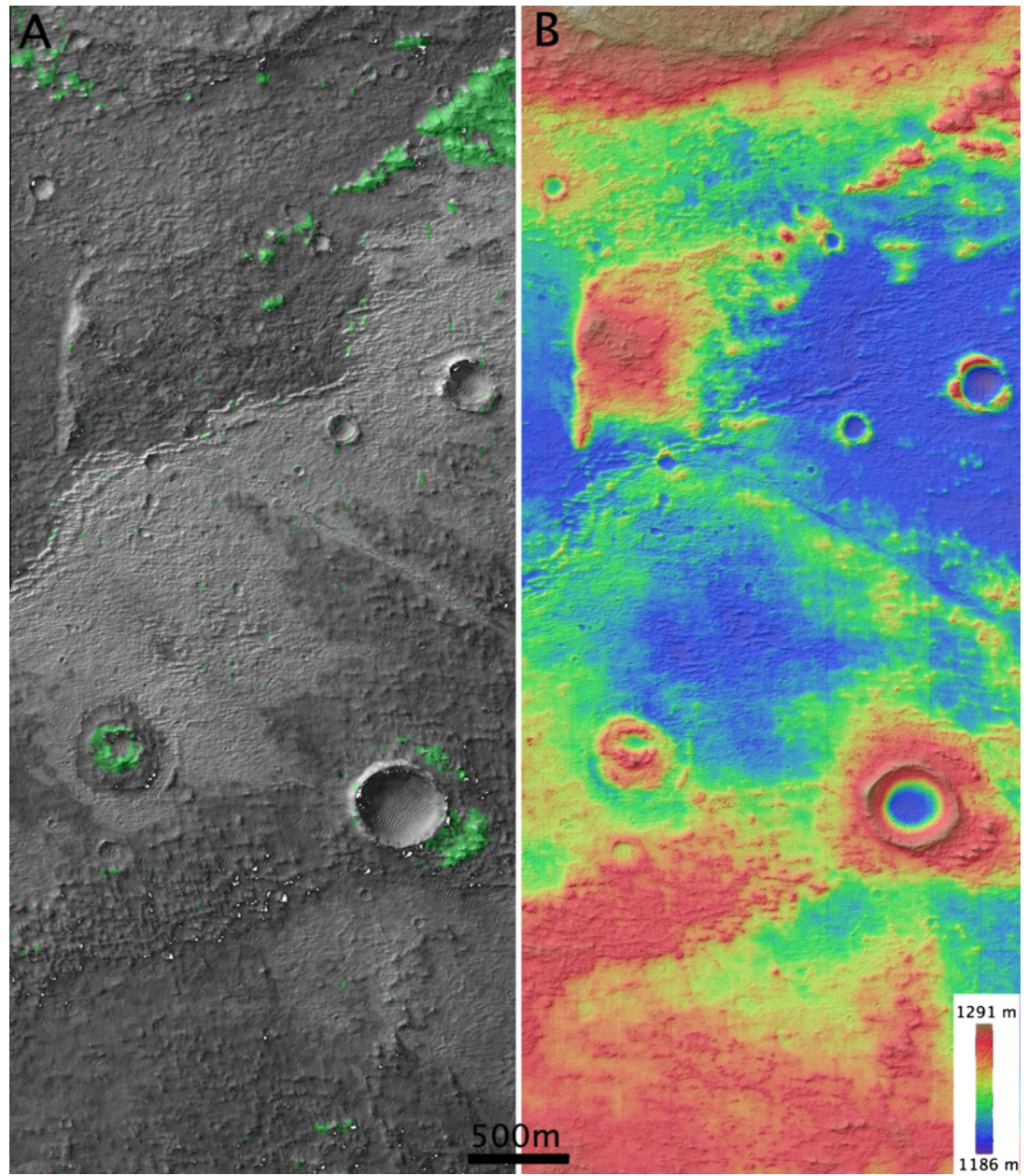

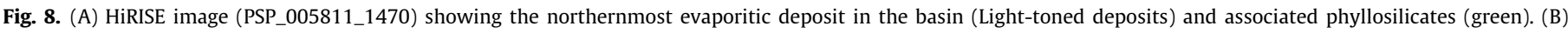

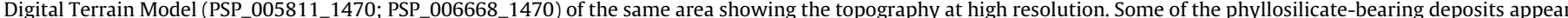

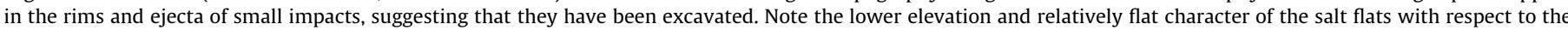

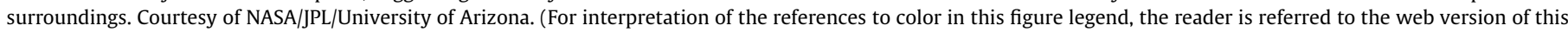
article.)

normal and inverted fluvial channels with fan deposits at their termini, as well as the occurrence of the deposits in the lowest topographic reaches, as encountered in aqueous environments of Earth where salts flats precipitate out of evaporating brines. The estimated area of these salt flats individually range between 10 and $50 \mathrm{~km}^{2}$, comparable in size to salt flats found on Earth in places such as the Atacama Desert, which also formed as a result of the evaporation of surface waters in structurally-controlled basins (Chong Diaz et al., 1999; Pueyo et al., 2001; Lowenstein et al., 2003). Additionally, salt flats in the Atacama are also typically marked by both normal and inverted fluvial channels.

Further evidence for aqueous activity include hydrated minerals (i.e., Fe/Mg-smectite-like spectral signatures), which occur near the salt flats in several parts of the basin. While the exact origin of the phyllosilicate-bearing deposits cannot be established with the available information, they do not appear to be directly associated with fluvial features, and thus do not appear to be transported from adjacent areas, but instead formed in situ within the basin. This is supported by the presence of phyllosilicates in the ejecta and rims of craters that impacted the salt flats (Fig. 8), suggesting that phyllosilicates could be more abundant beneath the evaporitic deposits, a sequence consistent with terrestrial cycles of siliciclastic deposition followed by evaporation.

All the salt flats and phyllosilicate-bearing deposits occur within the broad paleobasin, defined by the $1280 \mathrm{~m}$ topographic contour.
The southernmost salt flat is seemingly disconnected from this basin, but topographically it also lies below the $1280 \mathrm{~m}$ contour, and is connected to the deposits to the north by a fluvial channel. The slight dislocation of this deposit (approximately $50 \mathrm{~m}$-see Fig. 3) may be explained by a system of faults that could have influenced basin geometries and deformed older basin deposits, as well as influenced the drainage system such as the routing of water and deposition. The tectonic history is complicated not only by a complex fabric of basement structures such as the north-northwesttrending faults and ridges and the fault system of Sirenum Fossae, but also by the possible reactivation of the faults (Anderson et al., 2001). The system of fluvial channels shown in Fig. 8 also terminates abruptly at the same topographic contour, which also coincides with ridges and the ejecta blanket of large, highly degraded impact craters in the region. Topographically, the northernmost deposits of hydrated minerals (Fig. 7c) occur at $1330 \mathrm{~m}$, although this area has been affected by the same geologic processes that resulted in the formation of the fault system of Sirenum Fossae, and the actual topography may not reflect the original depositional altitude at which the hydrated minerals were deposited. The lowest-occurring deposits (Fig. 7d) at $1090 \mathrm{~m}$ provide a lower limit of the depth of the basin.

Based on this geomorphic and mineralogic information, we conclude that a relatively large body of liquid water once existed in this region, with a putative paleoshoreline at the $1280 \mathrm{~m}$ topographic contour. Our estimates are rather conservative (i.e., 


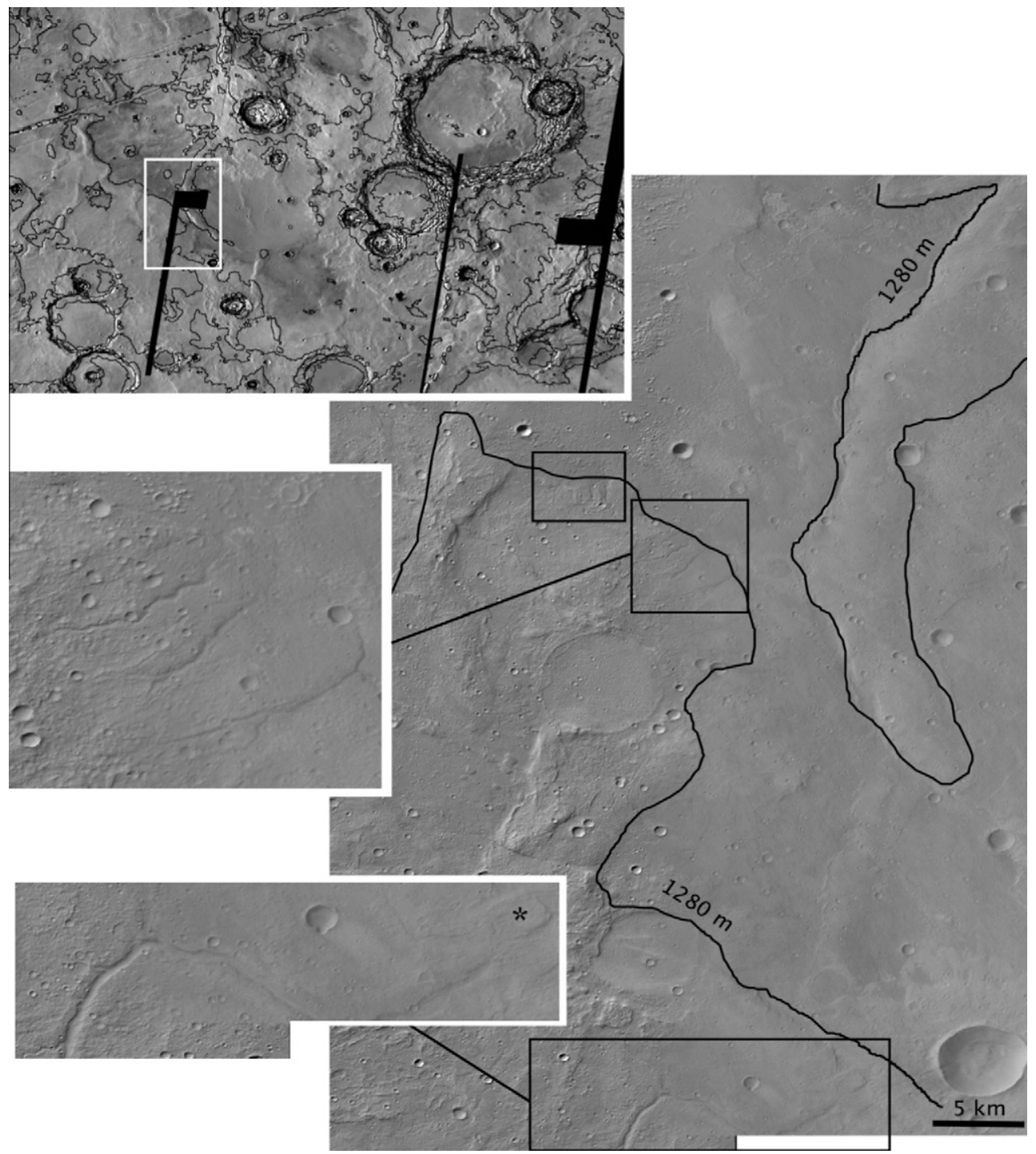

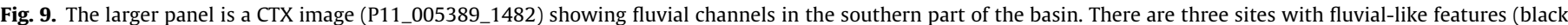

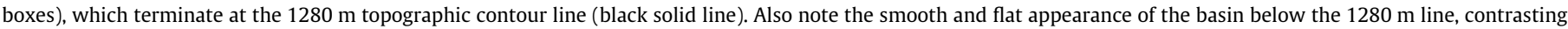

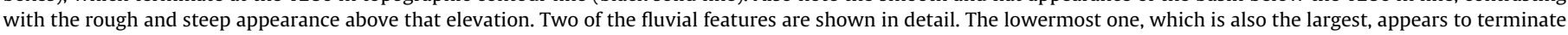
in a fan-like structure (star) that resembles a delta. The upper left image (THEMIS daytime IR) shows the location of this area within the basin (white box).

the basin could have been more extensive), since they are based on the current geomorphology and the distribution of aqueous minerals, both of which have likely been affected by a number of geologic processes, including impact cratering, mass wasting, and tectonism. For example, the proposed paleolake basin is segmented by a large impact crater whose ejecta partly covers some of the Fe/ Mg-smectites, making the determination of the extent of the basin tenuous. Taking the topographically lowest hydrated deposit inside the basin, we estimate a depth and an areal extent of at least $200 \mathrm{~m}$ and $30,000 \mathrm{~km}^{2}$, respectively. Aqueous activity likely extended beyond the primary basin reported here, but evidence has been obscured by geologic processes that subsequently altered the basin and its surroundings. For example, large north-northwest-trending faults that deformed the Terra Sirenum province (Dohm et al., 2002) influence the local geology, hydrogeology, and topography. At a smaller scale, north-northwest-trending ridges running parallel to faults inside the basin (see Fig. 3), also played a key role in the evolution of the basin, which includes deformation of older materials and control on drainage and deposition of subsequent fluvial activity.
Crater count statistics indicate an average surface age of the basin to be $3.95 \pm 0.1 \mathrm{Ga}$, correlative with Late Noachian aqueous activity in the basin, based on the chronology model of Hartmann and Neukum (2001). Deposits in the basin were seemingly resurfaced at a later stage $(3.6+0.06 /-0.11 \mathrm{Ga})$, and possibly in very recent times ( $313 \pm 100 \mathrm{Ma})$, although the mechanisms responsible for these resurfacing events are not known and are beyond the scope of this work. Therefore, the evaporitic and hydrated deposits in this basin are a window into the aqueous conditions on the highlands of Mars during the Noachian Period. The nature and distribution of the deposits in the basin indicates that during the Late Noachian, the water table was very close to the surface, at least locally. The presence of fluvial channels debouching into the basin to form salt flats and the Fe/Mg-smectite deposits point to an active hydrological cycle, at least in some regions of the southern highlands. This is consistent with the presence of a large paleolake basin at the source region of Ma'adim Vallis, located to the northwest of the basin described here, evidence for a long-term, stable highland water table during the Noachian Period (Irwin et al., 2002). The surface area and the estimated depth of these basins 


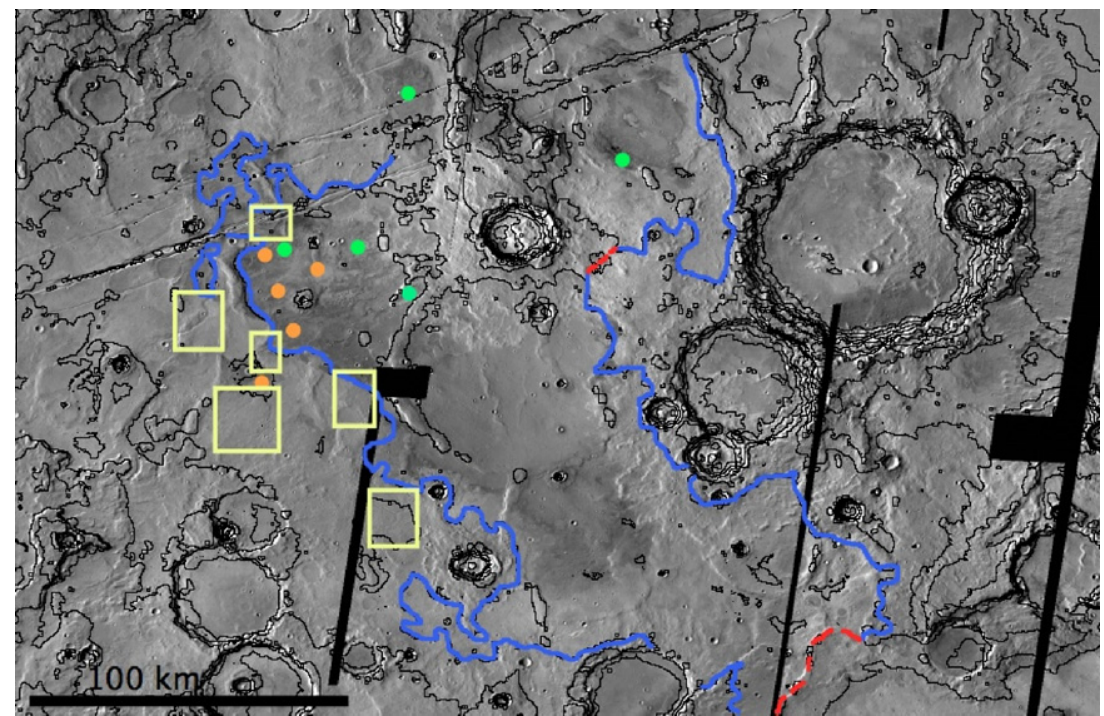

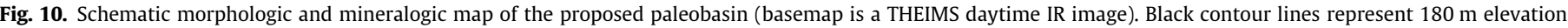

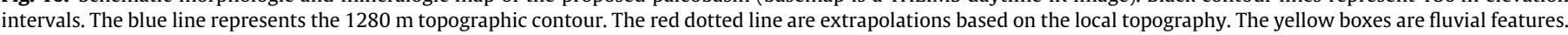

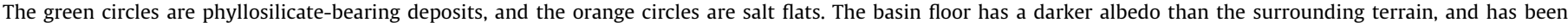

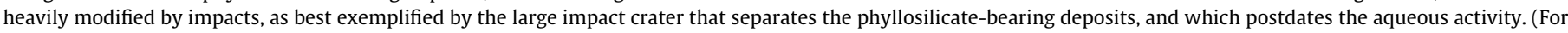
interpretation of the references to color in this figure legend, the reader is referred to the web version of this article.)
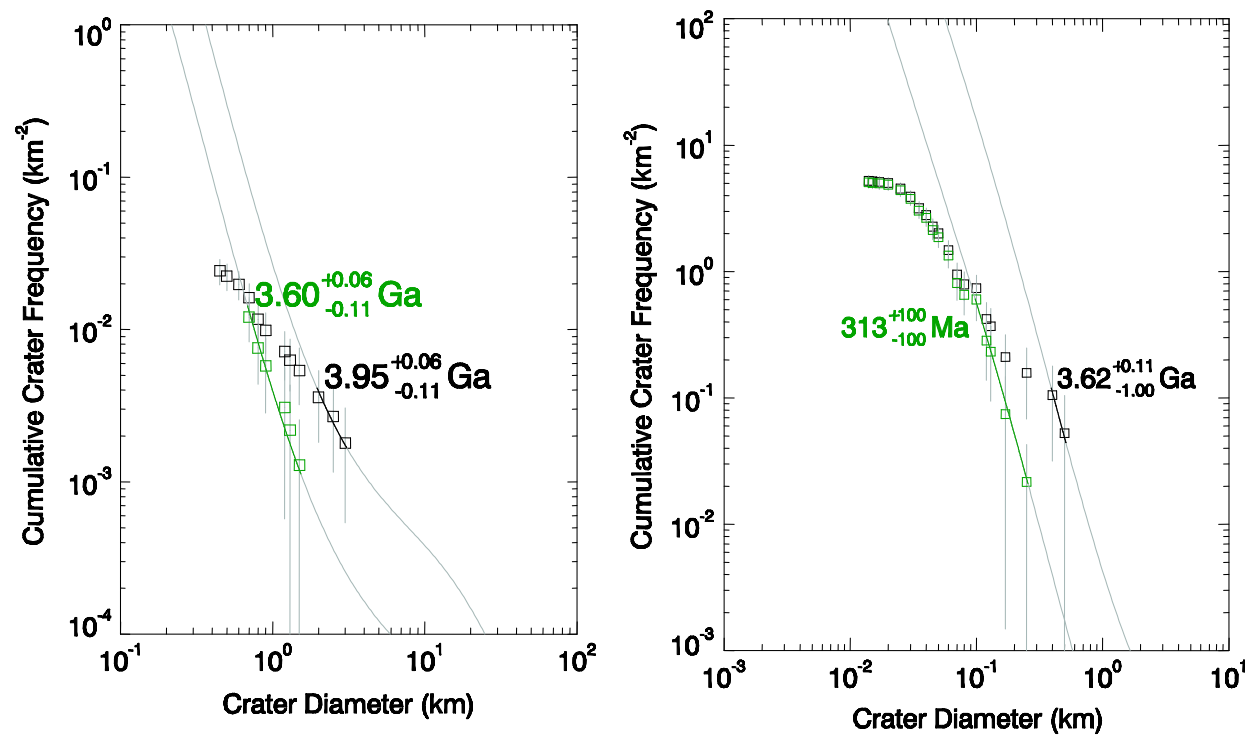

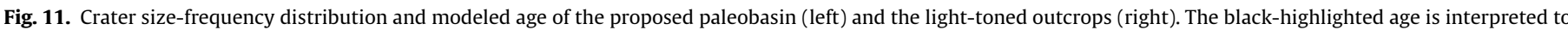

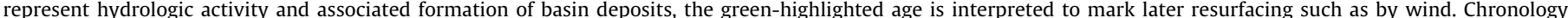

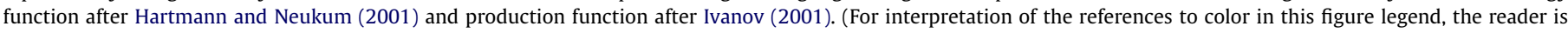
referred to the web version of this article.)

are equivalent to seas and large lakes on Earth, demonstrating that large bodies of liquid water were stable and possibly long lived early in the history of the planet.

The salt flats in the basin are particularly relevant for astrobiology due to their similarity to terrestrial environments where life is abundant (Rothschild, 1990; Wierzchos et al., 2006). Perfect examples are the evaporitic deposits found in the structurally-controlled basins of the Altiplano-Puna region in the Central Andes. Among these are the Salares (salt flats) in the Atacama Desert (Chong Diaz et al., 1999; Lowenstein et al., 2003), which have been recently identified as an important niche for life in the extreme arid conditions of the Atacama Desert (Wierzchos et al., 2006; Davila et al., 2008; de los Rios et al., 2010). Life thrives here due to the hygroscopic properties of the salts, which facilitate the occurrence of liquid water at low relative humidity (Wierzchos et al., 2006; Davila et al., 2008). Depending on their composition, the evaporitic deposits described here would interact with the atmospheric water vapor in a manner similar to those in the Atacama Desert, and could spontaneously form a saturated solution when the ambient relative humidity reaches the deliquescence relative humidity of particular salts (Davila et al., 2010). As we go back in time, the martian atmosphere was likely thicker and more moist, as evidenced by the large number of fluvial and lacustrine features (e.g., Scott et al., 1995; Carr, 1996; Cabrol and Grin, 1999) as well as widespread secondary minerals in ancient terrains (Poulet et al., 2005; Bibring et al., 2006; Mustard et al., 2008). The results presented here support existing models suggesting that Mars transitioned from a wet planet capable to sustain relatively large 
volumes of liquid water on the surface to the cold hyper-arid desert we see today (Bibring et al., 2006). Along this transition, the planet necessarily had to cross environmental conditions similar to deserts on Earth such as the Atacama. During such periods, the habitability of evaporitic deposits and the potential for microbial activity would have been higher (Rothschild, 1990). The potential of these deposits to provide a local habitable niche even under present day conditions (Davila et al., 2010), together with the fact that evaporitic deposits are good environments to preserve biomarkers (Rothschild, 1990), make the basin an ideal target for future life detection missions.

\section{Acknowledgments}

We wish to thank the comments and suggestions of two anonymous reviewers, which greatly improved the manuscript. Research by C.G. and T.K. was supported by the Helmholtz Association through the research alliance "Planetary Evolution and Life".

\section{References}

Acuña, M.H. et al., 1999. Global distribution of crustal magnetization discovered by the Mars Global Surveyor MAG/ER experiment. Science 284, 790-793.

Acuña, M.H. et al., 2001. Magnetic field of Mars: Summary of results from the aerobraking and mapping orbits. J. Geophys. Res. 106, 23403-23417.

Anderson, R.C., Dohm, J.M., Golombek, M.P., Haldemann, A., Franklin, B.J., Tanaka, K.L., Lias, J., Peer, B., 2001. Significant centers of tectonic activity through time for the western hemisphere of Mars. J. Geophys. Res. 106, 20563-20585.

Baldwin, R.B., 1964. Lunar crater counts. Astron. J. 69, 377-393.

Bibring, J. et al., 2006. Global Mineralogical and Aqueous Mars History Derived from OMEGA/Mars Express Data. Science 312, 400-404.

Bishop, J.L., Pieters, C.M., Edwards, J.O., 1994. Infrared spectroscopic analyses on the nature of water in montmorillonite. Clays Clay Miner. 42, 701-715.

Cabrol, N.A., Grin, E.A., 1999. Distribution, classification, and ages of martian impact crater lakes. Icarus $142(1), 160-172$.

Cabrol, N.A., Wynn-Williams, D.D., Crawford, D.A., Grin, E.A., 2001. Recent aqueous environments in martian impact craters: An astrobiological perspective. Icarus $154,98-113$

Carr, M.H., 1996. Water on Mars. Oxford University Press, USA.

Carr, M.H., Clow, G.D., 1981. Martian channels and valleys: Their characteristics, distribution, and age. Icarus 48, 91-117.

Chong Diaz, G., Mendoza, M., Garcia-Veigas, J., Pueyo, J.J., Turner, P., 1999. Evolution and geochemical signatures in a Neogene forearc evaporitic basin: the Sala Grande (Central Andes of Chile). Paleogeogr., Paleoclimatol., Paleoecol. 151, 39 54.

Christensen, P.R. et al., 2003. Morphology and composition of the surface of Mars: Mars Odyssey THEMIS results. Science 300 (5628), 2056-2061.

Clark, R.N., King, T.V.V., Klejwa, M., Swayze, G.A., 1990. High spectral resolution reflectance spectroscopy of minerals. J. Geophys. Res. 95, 12653-12680.

Connerney, J.E.P., Acuña, M.H., Wasilewski, P.J., Ness, N.F., Réme, H., Mazelle, C. Vignes, D., Lin, R.P., Mitchell, D.L., Cloutier, P.A., 1999. Magnetic lineations in the ancient crust of Mars. Science 284, 794-798.

Davila, A.F., Gomez-Silva, B., de los Rios, A., Ascaso, C., Olivares, H., McKay, C.P., Wierzchos, J., 2008. Facilitation of endolithic microbial survival in the hyperarid core of the Atacama Desert by mineral deliquescence. J. Geophys. Res. Biogeosci. 113. doi:10.1029/2007JG000561.

Davila, A.F. et al., 2010. Hygroscopic salts and the potential for life on Mars. Astrobiology 10, 617-628. doi:10.1089/ast.2009.0421.

de los Rios, A., Valea, S., Ascaso, C., Davila, A.F., Kastovsky, J., McKay, C., Gomez-Silva, B., Wierzchos, J., 2010. Comparative analysis of the microbial communities inhabiting halite evaporites of the Atacama desert. Int. microbiol. 13, 79-89.

Di Achille, G., Hynek, B.M., 2010. Ancient Ocean on Mars supported by global distribution of deltas and valleys. Nat. Geosci.. doi:10.1038/ngeo891.

Dohm, J.M., Maruyama, S., Baker, V.R., Anderson, R.C., Ferris, J.C., Hare, T.M., 2002 Plate tectonism on early Mars: Diverse geological and geophysical evidence. Lunar Planet. Sci. XXXIII. Abstract \#1639 (CD-ROM).

Dohm, J.M. et al., 2009. GRS evidence and the possibility of ancient oceans on Mars Planet. Space Sci. 57, 664-684.

Ehlmann, B.L. et al., 2009. Identification of hydrated silicate minerals on Mars using MRO-CRISM: Geologic context near Nili Fossae and implications for aqueous alteration. J. Geophys. Res. 114, E00D08. doi:10.1029/2009JE003339.

Fairén, A.G., Dohm, J.M., Baker, V.R., de Pablo, M.A., Ruiz, J., Ferris, J.C., Anderson, R.C., 2003. Episodic flood inundations of the northern plains of Mars. Icarus 165 53-67.

Fairén, A.G. et al., 2010. Phyllosilicates in impact craters on Mars: Pre- or postimpact Genesis? PNAS 107, 12095-12100. doi:10.1073/pnas.1002889107.

Gendrin, A. et al., 2005. Sulfates in martian layered terrains: The OMEGA/Mars Express view. Science 307 (5715), 1587-1591.

Grant, J.A. et al., 2008. HiRISE imaging of impact megabreccia and sub-meter aqueous strata in Holden Crater, Mars. Geology 36 (3), 195-198.
Hartmann, W.K., 1965. Terrestrial and lunar flux of large meteorites in the last two billion years. Icarus 4, 157-165.

Hartmann, W.K., Neukum, G., 2001. Cratering chronology and the evolution of Mars. Space Sci. Rev. 96, 165-194.

Irwin III, R.P., Maxwell, T.A., Howard, A.D., Craddock, R.A., Leverington, D.W., 2002. A large paleolake basin at the head of Ma'adim Vallis. Mars. Science, 296, 22092212.

Ivanov, B.A., 2001. Mars/moon cratering rate ratio estimates. In: Kallenbach, R. et al. (Eds.), Chronology and evolution of Mars: Dordrecht. Kluwer, pp. 87-104.

Kneissl, T., van Gasselt, S., Neukum, G., 2010. Map-projection-independent crater size-frequency determination in GIS environments - New software tool for ArcGIS. Planet. Space Sci., in press, doi:10.1016/j.pss.2010.03.015.

Lowenstein, T.K., Hein, M.C., Bobst, A.L., Jordon, T.E., Ku, T.-L., Luo, S., 2003. An assessment of stratigraphic completeness in climate-sensitive closed-basin lake sediments: Salar de Atacama, Chile. J. Sediment. Res. 73, 91-104.

Malin, M.C., Edgett, K.S., 2001. Mars Global Surveyor Mars Orbiter Camera: Interplanetary cruise through primary mission. J. Geophys. Res. 106, 2342923570.

Malin, M.C. et al, 2007. Context Camera Investigation on board the Mars Reconnaissance Orbiter. J. Geophys. Res. 112, E05S04. doi:10.1029/ 2006JE002808.

Marzo, G.A., Davila, A.F., Tornabene, L.L., Dohm, J.M., Fairén, A.G., Gross, C., Kneissl, T., Bishop, J.L., Roush, T.L., McKay, C.P., 2010. Evidence for Hesperian impactinduced hydrothermalism on Mars. Icarus 208, 667-683.

Masursky, H., Boyce, J.M., Dial, A.L., Schaber, G.G., Strobell, M.E., 1977. Classification and time of formation of martian channels based on viking data. J. Geophys. Res. 82 (28), 4016-4038.

McEwen, A.S. et al., 2007. Mars Reconnaissance Orbiter's High Resolution Imaging Science Experiment (HiRISE). J. Geophys. Res. 112, E05S02. doi:10.1029/ 2005JE002605.

McGuire, P.C. et al., 2009. An improvement to the volcano-scan algorithm for atmospheric correction of CRISM and OMEGA spectral data. Planet. Space Sci. 57, 809-815.

Michael, G.G., Neukum, G., 2010. Planetary surface dating from crater sizefrequency distribution measurements: Partial resurfacing events and statistical age uncertainty. Earth Planet. Sci. Lett. 294, 223-229.

Murchie, S. et al., 2007. CRISM (Compact Reconnaissance Imaging Spectrometer for Mars) on MRO (Mars Reconnaissance Orbiter. J. Geophys. Res. 112, 1-57.

Murchie, S.L. et al., 2009. A synthesis of martian aqueous mineralogy after 1 Mars year of observations from the Mars Reconnaissance Orbiter. J. Geophys. Res. 114, E00D06. doi:10.1029/2009JE003342.

Mustard, J.F. et al., 2008. Hydrated silicate minerals on Mars observed by the Mars Reconnaissance Orbiter CRISM instrument. Nature 454, 305-309.

Oepik, E.J., 1960. The lunar surface as an impact counter. Mon. Not. R. Astron. Soc. 120, 404-411.

Orofino, V., Goldspeil, J., Carofalo, I., Blanco, A., Fonti, S., Marzo, G.A., 2009. Evaluation of Carbonate abundance in putative martian paleolake basins. Icarus 200, 426-435. doi:10.1016/j.icarus.2008.11.020.

Osterloo, M.M., Hamilton, V.E., Bandfield, J.L., Glotch, T.D., Baldridge, A.M., Christensen, P.R., Tornabene, L.L., Anderson, F.S., 2008. Chloride-bearing materials in the southern highlands of Mars. Science 319, 1651-1654. doi:10.1126/science.1150690.

Osterloo, M.M., Anderson, F.S., Hamilton, V.E., Hynek, B.M., 2010. Geologic context of proposed chloride-bearing materials on Mars. J. Geophys. Res. 115, E10012. doi:10.1029/2010JE003613.

Pelkey, S.M. et al., 2007. CRISM multispectral summary products: Parameterizing mineral diversity on Mars from reflectance. J. Geophys. Res. 112, E08S14.

Poulet, F., Bibring, J.P., Mustard, J., Gendrin, A., Mangold, N., Langevin, Y., Arvidson, R.E., Gondet, B., Gomez, C., 2005. Phyllosilicates on Mars and implications for early martian climate. Nature 438, 623-627.

Pueyo, J.J., Chong, G., Jensen, A., 2001. Neogene evaporites in desert volcanic environments: Atacama Desert, northern Chile. Sedimentology 48, 1411-1431. doi:10.1046/j.1365-3091.2001.00428.x.

Putzig, N.E., Mellon, M.T., Kretke, K.A., Arvidson, R.E., 2005. Global thermal inertia and surface properties of Mars from MGS mapping missions. Icarus 173, 325341

Rothschild, L.J., 1990. Earth analogs for martian life: Microbes in evaporites, a new model system for life on Mars. Icarus 88, 246-260.

Scott, D.H., Tanaka, K.L., 1986. Geologic map of the western equatorial region of Mars. USGS Misc. Inv. Ser. Map I-1802-A (1:15,000,000).

Scott, D.H., Dohm, J.M., Rice Jr., J.W., 1995. Map of Mars showing channels and possible paleolake basins. USGS Misc. Inv. Ser. Map I-2461 (1:30,000,000).

Shoemaker, E.M., Hackman, R., Eggleton, R., 1962. Interplanteary correlation of geologic time. Adv. Astronaut. Sci. 8, 70-89.

Squyres, S.W. et al., 2004. In situ evidence for an ancient aqueous environment at Meridiani Planum, Mars. Science 306, 1709-1714.

Wierzchos, J., Ascaso, C., McKay, C.P., 2006. Endolithic cyanobacteria in halite rocks from the hyperarid core of the Atacama Desert. Astrobiology 6 (3), 415-422.

Wray, J.J., Murchie, S.L., Squyres, S.W., Seelos, F.P., Tornabene, L.L., 2009. Diverse aqueous environments on ancient Mars revealed in the southern highlands. Geology 37 (11), 1043-1046.

Zuber, M.T. 2001. The crust and mantle of Mars. Nature 412, 220-227.

Zuber, M.T., Smith, D.E., Solomon, S.C., Muhleman, D.O., Head, J.W., Garvin, J.B., Abshire, J.B., Bufton, J.L., 1992. The Mars observer laser altimeter investigation. J. Geophys. Res. 97, 7781-7797. 